\title{
Advances in the study of CAR-T in digestive system malignancies
}

\author{
Zhengchao Zhang ${ }^{1,2}$ and Yumin $\mathrm{Li}^{1,2}$ \\ ${ }^{1}$ Department of General Surgery, Lanzhou University Second Hospital, Lanzhou 730000, China \\ ${ }^{2}$ Key Laboratory of Digestive System Tumors of Gansu Province, Lanzhou 730000, China
}

\begin{abstract}
In recent years, tumor immunotherapy has obtained remarkable outcomes in the treatment of hematologic malignancies, tumor immunotherapy has been gradually applied to digestive system malignancies (DSMs) and has achieved some results. Chimeric antigen receptor T cells (CAR-T) is a gene-engineered receptor technology that integrates the antibody fragment of malignancy antigen and $\mathrm{T}$ cell activation domain to target and kill malignancy cells. CAR-T has been proved to be a strong killer of malignancies in B-cell leukemia and lymphoma. Therefore, a large number of research centers around the world have begun to focus on the application of CAR-T technology in DSMs, and their research has confirmed that CAR-T technology has a clear effect on the treatment of DSMs. Through reading a large number of literatures, we summarized the progress of CAR-T technology and its application in DSMs.
\end{abstract}

\section{Introduction}

All the time, the incidence of malignancy has been on the rise and has become a major public health problem worldwide. The malignancy statistics shown that in 2018 , there were 1735,350 new malignancy cases and 609,640 malignancy deaths in the United States [1]. Statistics shown that there were 4300000 new malignancy cases and 2900000 malignancy deaths in China in 2018. Compared with the United States, China had a lower incidence of malignancy, but a higher mortality of malignancy. 36.4 percent of malignancy-related deaths were from DSMs. By comparison, malignancy deaths of the digestive system account for only 5 percent of all malignancy deaths in the United States. The high mortality of the DSMS in China is mainly due to the low diagnosis rate of early malignancy and the inconsistent treatment strategies [2]. The early diagnosis rate of DSMS is low, and the treatment methods adopted in the face of advanced cases mainly include surgery, radiotherapy, and chemotherapy. Some of these patients miss surgery, so the 5-year survival rate for such patients is low. Facing with this situation, new treatments are urgently needed. In recent years, the immune therapy in the treatment of malignancy has obtained the remarkable results, including immune checkpoint inhibitors, monoclonal antibodies, activated lymphocyte cell factor, tumor vaccines, soluble malignancy viruses and adoptive T cell therapy (ACTs). The ACTs in the field of malignancy treatment have turned into a revolutionary strategy [3]. After the success of CAR-T immunotherapy in B-cell-originated hematologic malignancies such as leukemia and lymphoma, CAR-T technology has also injected new vitality into immunotherapy for DSMS.

Two kinds products (Kymriah and Yescarta) of targeted CD19 have been developed on the basis of the CAR - T technology, approved by the United States food and drug administration (FDA) for the treatment of $\mathrm{B}$ cell acute lymphoblastic leukemia and B cell lymphoma [4]. However, due to the heterogeneity of tumors in the digestive system and the lack of specific antigens, CAR-T therapy currently faces many obstacles, such as the microenvironment of malignancy immunosuppression, targeted extracellular toxicity and limitation of specific antigens [5]. Researchers have applied a number of strategies and methods to try to overcome these obstacles, including knocking out PD-1 expression, improving CAR-T structure, and combining CAR-T with other therapies [6-8]. Despite these efforts, no CAR-T product have so far been clinically approved for the treatment of tumors in the digestive system. It is full of confidence that there are many clinical trials of CAR-T therapy for DSMS in the world [9], and Chinese CAR-T clinical studies on DSMS account for the majority. Here we focus on the current CAR-T technology, obstacles, strategies to overcome these obstacles, and review the current status of CAR-T therapy for DSMS.

\section{CAR-T immunotherapy technology}

CAR-T were genetically engineered by introducing the required chimeric antigen receptors (CARs). The basic CAR structure includes tumor antigen specifically binding domain (single-chain variable fragment, scFv), extracellular hinge domain, transmembrane domain, and intracellular signal domain [10,11]. Hinge and transmembrane domains are the connection between $\mathrm{scFv}$ and intracellular domains and play a crucial role in firmly fixing the entire CAR structure on the $\mathrm{T}$ cell membrane and transmitting activation signals from scFv to $\mathrm{T}$ cell [12]. Intracellular structure domain mainly includes the $\mathrm{CD} 3 \zeta$ immune receptor tyrosine base on activation sequence (ITAM) structure domain, taking charge the activation of T cells. CARs can specifically combine the targeted antigen and activate downstream signals with scFv. These signals are used to activate cytotoxic T cell against malignancy cells $[13,14]$.

${ }^{\star}$ Correspondence to: Yumin Li, Department of General Surgery, Lanzhou University Second Hospital, Lanzhou 730000, China , E-mail: liym@lzu.edu.cn

Key words: CAR-T, immunotherapy, digestive system malignancies, gastric carcinoma, colorectal carcinoma, Hepatic carcinoma, pancreatic carcinoma

Received: November 30, 2020; Accepted: December 10, 2020; Published: December 16, 2020 


\section{The basic structure of CAR-T}

The first-generation CAR is mediated by $\mathrm{T}$ cell activation through $\mathrm{CD} 3 \zeta$ tyrosine activation on the chain motif [15]. CD3 $\zeta$ provides signals for $\mathrm{T}$ cell activation and proliferation surround of tumor cells. However, studies have indicated that first-generation CAR has limited antitumor activity in vivo due to poor $\mathrm{T}$ cell activation [16,17]. The second-generation CAR connects new co-stimulatory signal to intracellular regions, which expands the activation signal of T cells [18]. A number of studies have demonstrated that the second-generation CAR combined with the co-stimulation signal has the uniform antigenspecific characteristic as the first-generation CAR, and the increased secretion of anti-apoptotic proteins also leads to the delay of $\mathrm{T}$ cell apoptosis with the stronger proliferation of $\mathrm{T}$ cells and more cytokine secretion. The most commonly used costimulatory molecules are CD28, CD137(4-1BB) and OX40. For strengthening the design of CAR-T, the third generation CAR was developed in the study, adding additional costimulus signals on the basis of the second-generation CAR. A number of studies have also used CD28 and CD137 co-stimulation domains simultaneously to achieve stronger and more durable $\mathrm{T}$ cell activation states (Table 1). Researchers have compared the results of the secondgeneration and third-generation CARs, and acquired satisfactory results [19]. They found that CAR-T connected to three intracellular signaling domains (CD3, CD28, and CD137) was better at promoting cytokine release than just one or two of these domains. However, studies on the construction of second-generation CAR T cells have found that CD28CAR $\mathrm{T}$ cells can induce $\mathrm{T}$ cell proliferation and growth for longer, and CD137-CAR T cells lead to early failure, limiting the anti-tumor function of the cells [20-22]. Therefore, in addition to the structure of CAR-T, the function of the connected domain also plays an important role in the function of CAR-T.

\section{Improved structure of CAR-T}

Faced with the heterogeneity and immunosuppressive microenvironment of solid malignancies, researchers developed the fourth generation CAR, which were further constructed or induced to release the transgenic products to target malignancy tissues when the CAR-T acted $[23,24]$. Local release of immunoregulatory molecules, such as cytokines (IL-12, IL-18) [25], which can improve the immunosuppressive malignancy microenvironment. IL-12 is a cytokine that is often overexpressed in CAR-T. It is an effective molecule that can enhance the secretion of interferon, granase and perforin by $\mathrm{T}$ cells, and recruit NK cells from byliners to eliminate malignancy cells that are not identified by CARs [26,27]. CAR-T assembled with IL-12 have shown higher anti-tumor efficacy and proliferation in several preclinical research, particularly in solid malignancies, compared with conventional CAR-T [28-30]. A phase I clinical trial using a targeted Muc16 CAR-T cell that secretes IL-12 has been conducted, with no adverse event observed, although the results reported show little clinical benefit [31]. Another cytokine is IL-18, which can induce T cells to express IFN [32]. In preclinical models, IL-18 expression can also increase the cytotoxic activity and amplification of $\mathrm{T}$ cells [33,34]. Therefore, the fourth generation CAR-T enhanced its anti-tumor ability by adding positive regulatory anti-tumor cytokines to CAR. It shown good ability in improving $\mathrm{T}$ cells enrichment, infiltration, and recruitment of peripheral immune cells to kill tumor cells in solid malignant tumors and is expected to become an important mean for the treatment of solid malignant tumors.

The application of CAR-T technology in the treatment of patients with advanced malignancies is also facing new challenges. On the one hand, due to the damage of malignancy itself and chemoradiotherapy, the function of organs is weak, and the immune environment of the body is unbalanced in these patients, which may lead to difficulties in the extraction and separation of peripheral blood T cells and poor quality of the separated T cells. On the other hand, the long design in vitro and culture cycle of CAR-T and its high cost, as well as the risk of production failure, which will greatly affect the therapeutic effect of malignancy. The researchers found that these limitations could be eliminated by the technology of allogeneic $T$ cells. Whereas endogenous TCR on allogeneic T cells recognizes alloantigen receptor, resulting in graft versus host disease. In addition, human leukocyte antigen (HLA)

Table 1. Summary of preclinical studies on CAR-T in DSMS

\begin{tabular}{|c|c|c|c|c|}
\hline Antigen & Malignancy types & The structure of the CAR - T & Co-stimulus domain & Reference \\
\hline AFP & $\mathrm{HCC}$ & second generation & CD28 & Liu et al., [105] \\
\hline CEA & $\mathrm{PC}$ & second generation & CD28 & Chmielewski et al., [99] \\
\hline Her-2 & CRC & third generation & CD28 and 4-1BB & Teng et al., [106] \\
\hline \multirow{2}{*}{ GPC-3 } & \multirow{2}{*}{$\mathrm{HCC}$} & first generation & CD28 & \multirow{2}{*}{ Gao et al., [102] } \\
\hline & & third generation & CD28 and 4-1BB & \\
\hline \multirow{3}{*}{ GPC-3 } & \multirow{3}{*}{$\mathrm{HCC}$} & first generation & CD28 & \multirow{3}{*}{ Li et al., [107] } \\
\hline & & second generation & CD28/4-1BB & \\
\hline & & third generation & CD28 and 4-1BB & \\
\hline GPC-3 & $\mathrm{HCC}$ & third generation & CD28 and 4-1BB & Jiang et al., [108] \\
\hline GPC-3 and ASGR-1 & $\mathrm{HCC}$ & third generation (double targets) & CD28 and 4-1BB & Chen et al., [109] \\
\hline \multirow{2}{*}{ Her-2 and CD24 } & \multirow{2}{*}{$\mathrm{PC}$} & second generation & CD28 & \multirow{2}{*}{ Maliar et al., [110] } \\
\hline & & third generation & CD28 and 4-1BB & \\
\hline NKG2D & GC & second generation & 4-1BB & Tao et al., [111] \\
\hline NKG2D & CRC & third generation & CD28 and 4-1BB & Deng et al., [92] \\
\hline Trop2, PD-L1 & GC & third generation (double targets ) & CD28 and 4-1BB & Zhao et al., [112] \\
\hline MSLN & GC & third generation & CD28 and DAP10 & Jiang et al., [85] \\
\hline Claudin 18.2 & GC & second generation & CD28/4-1BB & Jiang et al., [78] \\
\hline HER2 & GC & second generation & $4-1 \mathrm{BB}$ & Song et al., [113] \\
\hline PSCA & GC & third generation & CD28 and 4-1BB & Wu et al., [114] \\
\hline HER2 & GC & second generation & $4-1 \mathrm{BB}$ & Han et al., [115] \\
\hline FOLR1 & GC & second generation & $\mathrm{CD} 28$ & Kim et al., [116] \\
\hline
\end{tabular}


expression on the surface of allogeneic $\mathrm{T}$ cells causes rapid rejection by the host immune system. Therefore, simple and effective methods for multi-genome editing of T cells are needed. Ren et al., [35] used CRISPR/Cas9 system to destroy multiple genomic loci simultaneously to generate endogenous CAR-T with deletion of TCR and HLA I expression, which can be used as allogeneic CAR- $\mathrm{T}$ and further developing into universal CAR-T, also known as the fifth generation CAR-T. This technology can theoretically realize the application of universal CAR-T in the clinical treatment of multiple tumor patients, which means that it will be possible for CAR-T to transform from an individual product to a universal product, and it will also provide greater benefits and convenience for the clinic. However, as the fifth generation CAR-T technology has made little progress in the treatment of tumors, its efficacy and safety need to be verified by more preclinical studies.

\section{Obstacles of CAR-T therapy for solid malignancies}

In recent years, CAR-T has made remarkable achievements in the treatment of CD19-positive B-cell-derived leukemia and lymphoma. Therefore, more and more research teams are starting to get involved in the treatment of solid tumors by CAR-T, and gratifying achievements have been made in the pre-clinical research after efforts. However, the clinical application of CAR-T therapy in the treatment of solid malignancies still faces many obstacles. On the one hand, CAR-T activity is correlated with severe side effects, such as cytokine release syndrome and neurotoxicity, while the underlying mechanism remains unclear [36-38]. On the other hand, the reduction of anti-tumor efficacy of CAR-T in solid malignancies is mainly due to the immunosuppressive effects and physical barriers of malignancy microenvironment, which seriously reduce the activity of CAR-T [39-41]. Therefore, the safety and efficacy of CAR-T in the treatment of solid malignancies still need to be improved.

\section{Lack of specific antigen}

Due to the heterogeneity of solid malignancies, it is hard for CAR-T technology to specifically identify malignancy-related targets, which is a challenge to be overcome [42]. The antigens of solid malignancy cells are not malignancy specific, so they are not confined to malignancy cells, inducing the risk of non-malignancy toxicity to healthy tissue. As reported in the clinical trial of CAR-T for the treatment of solid malignancies, targeted Her2 CAR-T therapy in patients with lung metastasis from Her2 positive colon malignancy leaded to cytokine release syndrome due to Her2 expression in the pleura, resulting in patient death [43]. Therefore, the problem of specific targets should be solved first in the treatment of solid tumors by CAR-T technology. However, specific targets can hardly be found in solid tumors, only tumor-related targets can be found, which are highly expressed in target tumors and low in other normal tissues. This is also the reason why CAR-T has been unable to make breakthrough in solid tumor treatment.

Currently, there are several types of tumor-associated antigens used by CAR-T technology in the treatment of solid malignancies: (1) malignancy-related peptides produced by malignancy-specific mutation expression, such as type III mutant epidermal growth factor receptor (EGFRvIII) [44]; (2) Antigens caused by abnormal glycosylation patterns, such as Mucin-1 (MUC1) and Mucin-16 (MUC16) glycoprotein [31,45]; (3) Malignancy stromal/malignancy vascular-associated antigens, such as FAP[46]; (4) Healthy cells expressed low levels of malignancy-specific antigens, such as dioxo Ganglioside 2 (GD2) [47], mesothelin (MSLN) [48], Prostate-specific malignancy antigen (PSMA)[49], IL-13Ra2 [50]; (5) Glycoproteins with antigenic properties of human embryos, such as carcinogenic antigen (CEA) [51]. Among them, human epidermal growth factor receptor-2 (HER2), PSMA, GD2, IL-13Ra2, MSLN, MUC1, MUC16 and EGFRvIII are the most studied solid malignancy targeting antigens in clinical studies [52,53]. From these research practices, the necessity of exploring neoantigens and optimizing antigen specificity in the treatment of solid malignancies is emphasized.

\section{Inhibition of malignancy microenvironment}

The success of CAR-T in the treatment of hematologic malignancies is mainly due to the fact that hematologic malignancies are conducive to the diffusion and infiltration of CAR-T cells, thus solving the problem of CAR-T targeting. However, in order to kill solid malignant cells, Car-t cells must circulate through the blood and lymph nodes to reach specific tumor sites. Even when reaching the surface of a malignant tumor, the dense extracellular matrix limits CAR-T infiltration to some extent, thus preventing CAR-T cells from reaching their target cells [54]. Stromal cells are responsible for malignant tumor growth and angiogenesis by providing nutrients, growth factors, chemokines, and stroma, so they block antitumor therapy by promoting an immunosuppressive environment that inhibits $\mathrm{T}$ cells effector function [55]. In order to avoid the effect of extracellular matrix (ECM) on the infiltration of CAR-T cells into malignancies, local or intratumoral administration not only provides effective and long-lasting antitumor effects, but also bypassing dense tumor stroma and reducing the risk of systemic non-target poisoning [56,57]. However, this method of drug administration may also bring some problems such as inconvenient drug administration and peripheral free tumor cells escaping CAR-T cell killing.

Furthermore, Studies have indicated that chemokines exert a crucial function in limiting homing ability of T cell [58-62]. As we all know, Solid malignancies can secrete a good deal of chemokines, such as $\mathrm{C}-\mathrm{C}$ chemokine ligand 2(CCL2), but their corresponding receptor chemokines, CCR2b and CCR4, are sparingly distributed on adoptive $\mathrm{T}$ cell membranes, resulting in incapacity of homing to malignancy sites [63]. Solid tumors also secrete a variety of other chemokines, such as CXCL2, CXCL5, CXCL12, CCL22, and CCL28.These chemokines attract marrow derived suppressor cells (MDSC) and regulatory T cells (Tregs), the primary function of two types of immunosuppressive cells is to mediate the cytotoxicity of $\mathrm{T}$ cells in solid malignancies [64-66]. The presence of a mass of immunosuppressive cells, severely inhibited the cytotoxic effects of CAR-T and prevented malignancy tissue from recruiting other effector immune cells.

Besides, studies have shown that PD- 1 can trigger or inhibit signals that exert a crucial function in the malignancy environment by binding to PD-L1. The combination not only blocks the activation of T cells by inhibiting the activation signals of $\mathrm{T}$ cells, but also assists regulatory cell (Treg) to exert an inhibitory function and induce the transformation of helper $\mathrm{T}$ cells into Tregs. The widespread expression of PD-1/PD-L1 in various solid malignancies may be one of the primary cause for the poor efficacy of CAR-T technology in solid malignancies [67-69].

\section{Application of CAR-T therapy in patients with DSMs}

In the last decade, some studies have focused on the use of CAR-T in gastric carcinoma (GC), pancreas carcinoma (PC), colorectal carcinoma (CRC) and Hepatic carcinoma (HCC). Although CAR-T immunotherapy still has a number of barriers to solid malignancy targeting [70,71], more than 40 preclinical and clinical studies have been related to the application of CAR-T in DSMS (Table 1 and Table 2). 
Table 2. Summary of clinical trials of CAR-T in DSMS

\begin{tabular}{|c|c|c|c|c|c|c|}
\hline Antigen & Malignancy types & $\begin{array}{l}\text { Number of } \\
\text { patients (n) }\end{array}$ & $\begin{array}{l}\text { Clinical } \\
\text { stage }\end{array}$ & $\begin{array}{l}\text { Identifying code } \\
\text { (clinicaltrials.gov) }\end{array}$ & Sponsor & Status \\
\hline EPCAM & GC & 19 & II & NCT02725125 & Beijing Hua Wei Cell Therapy Co. LTD (China) & Recruiting \\
\hline EpCAM & GC & 40 & I & NCT03563326 & West China Hospital (China) & Recruiting \\
\hline ЕрСАM & $\begin{array}{l}\text { CRC, oesophageal } \\
\text { carcinoma, GC, HCC, PC }\end{array}$ & 60 & I and II & NCT03013712 & The first Affiliated Hospital of Chengdu Medical College (China) & Recruiting \\
\hline EPCAM & $\mathrm{HCC}$ & 25 & II & NCT02729493 & Beijing Hua Wei Cell Therapy Co. LTD (China) & Unknown \\
\hline Claudin 18.2 & $\mathrm{GC}, \mathrm{PC}$ & 2 & I & NCT03890198 & $\begin{array}{l}\text { First Affiliated Hospital of Xi 'an Jiaotong University, Nanjing Lenovo } \\
\text { Biotechnology Co. LTD (China) }\end{array}$ & Terminated \\
\hline Claudin 18.2 & GC, PC & 30 & I & NCT04404595 & Keji Biomedicine (Shanghai) Co., LTD (China) & Not yet recruiting \\
\hline MUC1 & $\mathrm{CRC}, \mathrm{GC}$ & 20 & I and II & NCT02617134 & $\begin{array}{l}\text { Persengen Biotherapy (Suzhou) Co. LTD, The First People's Hospital } \\
\text { of Hefei City, Hefei Binhu Hospital (China) }\end{array}$ & Unknown \\
\hline MUC1 & $\mathrm{HCC}, \mathrm{PC}$ & 200 & I and II & NCT02587689 & $\begin{array}{l}\text { Persengen Biotherapy (Suzhou) Co. LTD, The First People's Hospital } \\
\text { of Hefei City, } \\
\text { Hefei Binhu Hospital (China) }\end{array}$ & Unknown \\
\hline CEA & CRC, GC, HCC, PC & 40 & I and II & NCT04348643 & Chongqing Precision Biotechnology Co. LTD (China) & Recruiting \\
\hline CEA & CRC, GC, PC & 75 & I & NCT02349724 & Southwest China Hospital (China) & Unknown \\
\hline CEA & CRC, GCPC & 18 & I & NCT03682744 & Sorrento Therapeutics, Inc. (America) & Active, not recruiting \\
\hline CEA & liver metastases & 5 & I & NCT02850536 & $\begin{array}{l}\text { Roger Williams Medical Center (America) } \\
\text { University of Colorado, Denver } \\
\text { Sorrento Therapeutics, Inc }\end{array}$ & Active, not recruiting \\
\hline CEA & liver metastases & 8 & I & NCT02416466 & $\begin{array}{l}\text { Roger Williams Medical Center (America) } \\
\text { Sirtex Medical }\end{array}$ & Completed \\
\hline CEA & $\begin{array}{l}\text { hepatic metastasis in } \\
\text { pancreatic }\end{array}$ & 167 & II & NCT04037241 & Sorrento Therapeutics, Inc. (America) & Not yet recruiting \\
\hline CEA & $\mathrm{PC}$ & 6 & I & NCT03818165 & Sorrento Therapeutics, Inc. (America) & Active, not recruiting \\
\hline MSLN, & PC & 16 & I & NCT01897415 & University of Pennsylvania (America) & Completed \\
\hline MSLN, & $\mathrm{PC}$ & 20 & I & NCT02580747 & Chinese PLA General Hospital (China) & Unknown \\
\hline MSLN & PC & 30 & I & NCT02706782 & Shanghai Jikeiyin Chemical Technology Co., LTD (China) & Unknown \\
\hline MSLN/CD19 & $\mathrm{PC}$ & 10 & I & NCT03497819 & The first Affiliated Hospital of Wenzhou Medical University (China) & Active, not recruiting \\
\hline $\begin{array}{l}\text { MSLN, } \\
\text { PSCA, CEA, } \\
\text { HER2, MUC1, } \\
\text { EGFRvIII }\end{array}$ & PC & 10 & I & NCT03267173 & $\begin{array}{l}\text { The first Affiliated Hospital of Harbin Medical University, Shanghai } \\
\text { Ucadi Biomedical Technology Co., LTD (China) }\end{array}$ & Unknown \\
\hline GPC3 & $\mathrm{HCC}$ & 30 & I and II & NCT02715362 & Shanghai Jikeiyin Chemical Technology Co., LTD (China) & Unknown \\
\hline GPC3 & $\mathrm{HCC}$ & 20 & I & NCT04121273 & $\begin{array}{l}\text { Nanjing Gulou Hospital affiliated to Nanjing University Medical } \\
\text { College (China) }\end{array}$ & Recruiting \\
\hline GPC3 & $\mathrm{HCC}$ & 14 & I & NCT02905188 & $\begin{array}{l}\text { Baylor College of Medicine (America) } \\
\text { Center for Cell and Gene Therapy, Baylor College of Medicine } \\
\text { The Methodist Hospital System }\end{array}$ & Recruiting \\
\hline GPC3 & $\mathrm{HCC}$ & 30 & I & NCT03198546 & $\begin{array}{l}\text { Second Affiliated Hospital of Guangzhou Medical University, Hunan } \\
\text { Zhaotai Yongren Medical Innovation Co. LTD, } \\
\text { Guangdong Zhaotai Bio-pharmaceutical Co. LTD, The First Affiliated } \\
\text { Hospital of Sun Yat-sen University (China) }\end{array}$ & Recruiting \\
\hline GPC3 & $\mathrm{HCC}$ & 10 & I and II & NCT03130712 & $\begin{array}{l}\text { Shanghai Jikeiyin Chemical Technology Co., LTD, Beijing } 302 \\
\text { Hospital (China) }\end{array}$ & Unknown \\
\hline GPC3 & $\mathrm{HCC}$ & 60 & I and II & NCT02723942 & Guangzhou Fuda Malignancy Hospital (China) & Completed \\
\hline GPC3 & $\mathrm{HCC}$ & 13 & I & NCT02395250 & Shanghai Renji Hospital (China) & Completed \\
\hline GPC3 & $\mathrm{HCC}$ & 20 & I and II & NCT03084380 & Chongqing Xinqiao Hospital (China) & Unknown \\
\hline GPC3 & $\mathrm{HCC}$ & 36 & I & NCT03980288 & Zhejiang University, Kozic Cayman Medical Co., LTD (China) & Recruiting \\
\hline GPC3 & $\mathrm{HCC}$ & 15 & I & NCT03884751 & $\begin{array}{l}\text { Kozic Cayman Medical Co., LTD, Nanjing PLA } 81 \\
\text { Hospital, The First Affiliated Hospital of Zhejiang University, Ruijin } \\
\text { hospital (China) }\end{array}$ & Recruiting \\
\hline EGFR & CRC & 20 & I & NCT03542799 & $\begin{array}{l}\text { Shenzhen Second People's Hospital, Prujin (Shenzhen) Biotechnology } \\
\text { Co., LTD (China) }\end{array}$ & Not yet recruiting \\
\hline EGFR & CRC & 20 & I and II & NCT03152435 & $\begin{array}{l}\text { Shenzhen Second People's Hospital, Beijing Puruijie Technology Co. } \\
\text { LTD (China) }\end{array}$ & Unknown \\
\hline NKG2DL & $\mathrm{CRC}, \mathrm{GC}$ & 10 & I & NCT04107142 & CytoMed Therapeutics Pte Ltd (America) & Not yet recruiting \\
\hline NKG2D & HCC, CRC & 10 & I & NCT04270461 & Affiliated Hospital of Jiujiang University (China) & Not yet recruiting \\
\hline
\end{tabular}




\begin{tabular}{|c|c|c|c|c|c|c|}
\hline MSLN & $\mathrm{GC}$ & \multirow{3}{*}{50} & \multirow{3}{*}{ I and II } & \multirow{3}{*}{ NCT03941626 } & \multirow{3}{*}{$\begin{array}{l}\text { Shenzhen Binde Biotechnology Co. LTD, Henan Provincial People's } \\
\text { Hospital (China) }\end{array}$} & \multirow{3}{*}{ Recruiting } \\
\hline DR5 & $\mathrm{HCC}$ & & & & & \\
\hline EGFR vIII & $\mathrm{HCC}$ & & & & & \\
\hline DR5 & $\mathrm{HCC}$ & \multirow{4}{*}{73} & \multirow{4}{*}{ I and II } & \multirow{4}{*}{ NCT03638206 } & \multirow{4}{*}{$\begin{array}{l}\text { Shenzhen Binde Biotechnology Co. LTD, First Affiliated Hospital of } \\
\text { Zhengzhou University (China) }\end{array}$} & \multirow{4}{*}{ Recruiting } \\
\hline C-MET & $\mathrm{HCC}, \mathrm{CRC}$ & & & & & \\
\hline EGFR V III & $\mathrm{HCC}$ & & & & & \\
\hline MSLN & GC, PC & & & & & \\
\hline GPC3 & $\mathrm{HCC}$ & \multirow{3}{*}{20} & \multirow{3}{*}{ I and II } & \multirow{3}{*}{ NCT02959151 } & \multirow{3}{*}{$\begin{array}{l}\text { Shanghai Jikeiyin Chemical Technology Co., LTD, Shanghai } \\
\text { Malignancy Hospital (China) }\end{array}$} & \multirow{3}{*}{ Unknown } \\
\hline MSLN & $\mathrm{PC}$ & & & & & \\
\hline CEA & $\mathrm{CRC}$ & & & & & \\
\hline C-MET/PD-1 & $\mathrm{HCC}$ & 50 & I & NCT03672305 & The Second Hospital of Nanjing Medical University (China) & Not yet recruiting \\
\hline ROR2 & GC, PC & 18 & I & NCT03960060 & $\begin{array}{l}\text { Shanghai Puheng Biotechnology Co. LTD, Shanghai Zhongshan } \\
\text { Hospital (China) }\end{array}$ & Active, not recruiting \\
\hline Her-2 & $\begin{array}{l}\text { CRC, Oesophageal } \\
\text { carcinoma, GC, PC }\end{array}$ & 39 & I & NCT03740256 & Baylor College of Medicine (America) & Not yet recruiting \\
\hline PSCA & GC, $\mathrm{PC}$ & 151 & I and II & NCT02744287 & Bellicum Pharmaceuticals (America) & Recruiting \\
\hline AFP & $\mathrm{HCC}$ & 3 & I & NCT03349255 & $\begin{array}{l}\text { Aeon Biomedical (Shanghai) Co., LTD, People's Hospital of Wuhan } \\
\text { University, Unico Biotech (China) }\end{array}$ & Terminated \\
\hline MG7 & liver metastases & 20 & I and II & NCT02862704 & $\begin{array}{l}\text { Xijing Hospital, Shanghai Jikeiyin Chemical Technology Co., LTD } \\
\text { (China) }\end{array}$ & Unknown \\
\hline CD147 & $\mathrm{HCC}$ & 34 & I & NCT03993743 & Xijing Hospital (China) & Recruiting \\
\hline CD133 & $\mathrm{HCC}, \mathrm{PC}, \mathrm{CRC}$ & 20 & I and II & NCT02541370 & Chinese PLA General Hospital (China) & Completed \\
\hline
\end{tabular}

More than 10 malignancy-associated antigens have been used as targets for the treatment of tumors in the digestive system by CAR-T. Studies on malignancy-associated antigens such as CEA, GD2, MSLN, HER2, EGFR, and many other tumor antigens (FAP, IL-13Ra2, MUC1, PSCA, PSMA) have been reported. So far, most of the studies targeting these antigens have obtained definite anti-tumor properties in preclinical studies, but no breakthrough has been made in clinical trials.

\section{Gastric carcinoma}

Several antigens related gastric carcinoma (GC) have been identified in preclinical studies and applied to CAR-T studies. At present, common targets of CAR-T cell application in clinical trials of GC patients include HER2, CEA, Claudin18.2 (CLDN18.2), MSLN, MUC1 and Epithelial adhesion molecule (EpCAM), as well as clinical studies targeting PSCA, ROR2 and NKG2DL (Table 2).

HER2 exerts a crucial role in the pathogenesis of gastric, gastroesophageal malignancy and other types of malignancies [72,73]. HER2 gene amplification and overexpression of its protein product (p185-protein) were correlated with more than $30 \%$ of malignancies, while p185 protein expression was negative in normal tissues $[74,75]$. Therefore, HER 2 can be an promising target for malignancy therapy, and a number of preclinical studies targeting HER2-specific CAR-T have been conducted [76]. Relevant Phase I clinical study (NCT03740256) is being recruited to combine two different antitumor approaches: oncolytic adenovirus and targeted her2 CAR-T to assess the safety and efficacy in the treatment of GC (Table 2). CAR-T technology combined with other anti-tumor methods has been widely used in preclinical and clinical studies in order to achieve the functional complementary effect of the two anti-tumor methods.

CEA is a kind of acidic glycoprotein with the characteristics of human embryo antigen. It exists on the surface of malignancy cells differentiated from endoderm cells and is the structural protein of cell membrane. It is commonly expressed in the GC, PC, CRC and HCC tissues. Preclinical studies have confirmed that CEA-specific CAR-T cells infiltrate malignancies, kill malignancy cells, delay malignancy growth, and prolong the survival of GC mice [77]. Phase I-II clinical studies (NCT04348643, NCT02349724, AND NCT03682744) of targeted CEA CAR-T therapy for GC are under way, for assessing the efficacy and safety of targeted CEA CAR-T therapy and obtaining recommended doses and infusion regiments (Table 2). The progress of these clinical studies was slow due to the particularity of CAR-T technology. On the one hand, due to the immature treatment of CAR $\mathrm{T}$ in solid tumors, the recruitment time of patients is too long. On the other hand, the side effect of the drug in the clinical trial led to the termination of the study.

CLDN18.2 is a membrane protein and is highly expressing in the tissue of GC. Jiang et al. [78] prepared specific CLDN18.2 humanized antibody using hybridoma and humanization techniques. Targeted CLDN18.2 CAR-T were produced by lentivirus vector transduction. The killing tumor activity of CAR-T in GC cell lines were measured in vitro. Then CAR-T was used to test the anti-tumor activity in the tumor model of GC cell line transplantation and the tumor model of GC tissue transplantation. Both in vitro and in vivo have obtained significant curative effect. Two clinical studies (NCT03890198, NCT04404595) targeted CLDN18.2 CAR-T in patients with advanced stomach and pancreatic cancer have been conducted, and the objective of clinical studies is to assess safety, tolerability, pharmacokinetics, and efficacy, and immunogenicity of cell therapy for advanced gastric and pancreatic ductal adenocarcinoma (Table 2). One of the clinical studies has been discontinued due to clinical complications and the other has not yet been recruited. Which also shows that CAR-T has a long way to go in treating solid tumors.

MSLN, is a $40 \mathrm{kda}$ membrane protein, is highly expressed in mesothelioma, lung carcinoma, PC, mammary gland carcinoma, ovary carcinoma and GC $[79,80]$. So far, MSLN has been targeted for the treatment of solid malignancies including mesothelioma, GC, lung malignancy, breast malignancy and PC [48,81-84]. Jiang et al., [85] found that targeted MSLN CAR-T showed strong cytotoxicity and cytokine secretion ability on GC cells in vitro, induced GC regression in different xenograft mouse models, and prolonged the survival time of the mouse. However, in the subcutaneous model of gastric cancer, only local injection could improve the invasion of CAR-T in tumor tissues and significantly inhibit the growth of gastric cancer. Phase I-II studies (NCT03941626, NCT03638206) are recruiting, in order to assess the 
safety and efficacy of CAR-T immunotherapy in patients with GC (Table 2). The stomach is a lacunar internal organ, so due to its physiological structure characteristics, local administration of GC drugs will bring many difficulties. Therefore, CAR-T therapy for GC still requires efforts in intravenous administration, which requires enhancement of CAR-T tumor targeting, enrichment and infiltration.

MUC1 is a transmembrane glycoprotein that is highly expressed in GC. Wilkie et al., [86] constructed targeted MUC1 CAR-T and verified that which could effectively attack MUC1-positive malignancy cells. In addition, they constructed CAR-T with dual anti-ERBB2 and MUC1, which can effectively remove antigen-positive malignancy cells and modulate the immune microenvironment [87]. Phase I-II clinical studies targeting MUC1 (NCT02617134) are under way to assess the safety and efficacy of CAR-T immunotherapy in patients with muclpositive recurrence or refractory gastric and colorectal carcinoma (Table 2). CAR-T targeting multiple targets has been widely used in the treatment of solid tumors in recent years, and its biggest advantage is to prevent the off-target effect of tumors. Multi-target coverage not only enhances car- $\mathrm{T}$ targeting but also enhances its anti-tumor ability. However, as mentioned earlier, there are few specific antigens in solid tumors, and multi-target coverage will inevitably bring the risk of targeting extracellular cytotoxicity. Therefore, the multi-target treatment of CAR-T will be more stringent in the selection of target.

EpCAM is a transmembrane glycoprotein that is highly expressed in a variety of malignancies. Studies have found that changes in EpCAM expression are associated with invasive biological behavior in GC [88], so EpCAM is considered as a potential malignancy stem cell marker. Deng et al., [89] reported that targeted EpCAM CAR-T cells showed significant antitumor activity in prostate malignancy. Clinical Phase I-II studies related to GC (NCT02725125, NCT03563326, and NCT03013712) are being recruited and are expected to provide new treatment strategies for patients with peritoneal metastasis from GC. Among them, clinical studies (NCT03013712) targeting EpCAM also involved the treatment of CRC. In this study, adverse reactions, CAR-T persistence, and efficacy evaluation at 24 months after engineered $T$ cell infusion were studied (Table 2). As shown above, EpCAM belongs to a generic targeting antigen in the treatment of digestive system tumors by CAR-T, and it is expected to develop a generic car-T product for the digestive system by targeting EpCAM.

\section{Colorectal carcinoma}

Colorectal cancer (CRC) is one of the most common DSMS. Studies have shown that multiple tumor-associated antigens are overexpressed in CRC tissues, and some preclinical/clinical trials for CRC CAR-T are ongoing. There are 7 targets for CRC CAR-T therapy in clinical trials, including CEA, HER2, EpCAM, MUC1, CD133, Natural-killer group 2, member D (NKG2D), and C-MET (Table 2). In a preclinical study, CEA was studied as a malignancy-specific target as part of CAR-T therapy. Targeted CEA CAR-T have been demonstrated to enhance anti-tumor immunity of CEA colon malignancy cells in mice and humans [77]. Related clinical Phase I-II studies (NCT02725125, NCT03563326, and NCT03013712) are being recruited and are expected to provide novel treatment strategies for patients with advanced CRC (Table 2). Because of the specific expression of CEA in CRC, researchers have not given up the research on targeting CEA CAR-T in colorectal cancer. It is believed that new gains will be made with the deepening of the research.

HER2, a transmembrane glycoprotein belonging to the ErbB family is associated with malignancy development. Previous clinical studies targeting HER2 CAR-T for CRC have failed due to the cytotoxicity of targeting extracellular tissues. However, the high expression of HER2 in CRC urges people to continuously optimize anti-HER2 CAR-T. Recently, the relevant phase I clinical study (NCT03740256) prepared by Baylor College of Medicine in the United States will be used to evaluate the safety and efficacy of anti-Her 2 CAR-T combined with oncolytic adenovirus in CRC, esophageal malignancy, GC and PC (Table 2).

NKG2D is an important activated receptor expressed on the surfaces of NK cells, formation-blocking T cells, CD8+T cells, and some autoreactive or immunosuppressive CD4+T cells [90]. The molecule appear at low or undetectable levels in normal cells, but rapidly appear on the surface of infected or malignant cells [91]. NKG2D activates immune cells through the adaptor molecule DAP10, which triggers cell proliferation, proinflammatory cytokine production, and target cell elimination. These functions underscore the importance of NKG2D in tumor immunotherapy. Deng et al., [92] investigated the anti-tumor activity of targeted NKG2D CAR-T on human CRC cells by constructing the third generation CAR-T. In vitro experiments, targeted NKG2D CAR-T showed dose-dependent cytotoxicity in human CRC cells compared with untransfected $\mathrm{T}$ cells. In vivo, targeted NKG2D CAR-T significantly inhibited malignancy growth, reduced malignancy size, and extended the overall survival of mice transplanted with HCT-116 cells. No serious lesions were found in all the treatment groups. NKG2D CAR-T are a promising immunotherapy strategy for human CRC. At present, there have been many preclinical studies on immunotherapy for CRC using NKG2DL CAR-T [93]. A Phase I clinical study (NCT04270461) in China to assess the efficacy and safety of HCC and CRC based on NKG2D is under way. A phase I clinical study of targeted NKG2DL CAR-T cells in the treatment of recurrent or refractory colorectal and gastric carcinoma (NCT04107142) is also underway in the United States to assess its safety and tolerability (Table 2). CAR-t therapy targeting NKG2D is also widely used in digestive system tumors, such as GC, CRC and HCC (Table 1, and Table 2).

c-MET is expressed in epithelial cells, endothelial cells, neurons, hepatocytes, and hematopoietic cells. c-MET exerts a crucial function in the proliferation and progression of malignancy cells [94]. c-MET is correlated with the survival, invasion and metastasis of malignancy. c-MET is overexpressed in diverse solid malignancies, such as HCC, breast carcinoma, lung carcinoma, and CRC [95]. Currently, there are few CAR-T studies targeting c-MET, and the only clinical I and II study of c-MET CAR-T for CRC and HCC is being carried out in China (NCT03638206) (Table 2).

\section{Pancreatic carcinoma}

Pancreatic carcinoma (PC)is a malignancy of the digestive system, characterized by high degree of malignancy and short course of disease. At present, there are many studies on the application of CAR-T technology to treat $\mathrm{PC}$ targeting different antigens. Because of its specific expression in pancreatic cancer, MSLN has become one of the most studied targets. In animal experiments, CAR-T specifically targeting MSLN showed strong antitumor activity [96]. In preclinical trials, new targets related to PC were also developed, including Claudin18.2, CEA, HER2, EGFRvIII, EpCAM, MUC1, CD133, etc. (Table 2). Many studies have improved CAR structures based on these targets in order to achieve better efficacy.

Prostate stem cell antigen (PSCA) is over expressed in several malignancies, such as prostate carcinoma, bladder carcinoma, and PC. Nevertheless, PSCA expression is low in normal cells, So, it has the ability to be a car- $\mathrm{T}$ target. Researchers designed the second-generation 
PSCA CAR-T, which have been proved to be capable of eradicate PSCA-positive PC cells in vivo and in vitro, but, have no obvious effect on PSCA-negative PC cells [97]. Daniel et al., [98] proved in their study that targeted PSCA CAR-T can reduce the volume of malignant tumor by blocking the growth pathway of tumor cells. Clinical studies targeted PSCA (NCT02744287) are being recruited to evaluate the safety and activity of targeted PSCA CAR-T in the treatment of advanced solid malignancies, including PC, GC, prostate carcinoma (Table 2).

Targeted CEA CAR-T designed by Chmielewski et al., [99] were able to continuously recognize and attack malignancy cells, obviously reducing the size of pancreatic malignancies. In the mouse model, $67 \%$ of the malignancy cells were reported to be cleared, with no obvious damage to other healthy tissues. Targeted Muc1 CAR-T has been shown to have significant antitumor effects in preclinical studies for the treatment of PC [100]. Meanwhile, clinical studies on the above targets are also under way (Table 2), and it is expected to be successful in the treatment of PC.

\section{Hepatic carcinoma}

Hepatic carcinoma (HCC) consists of primary and metastatic carcinoma. HCV and HBV infection are the main causes of liver cancer. Burga et al., [101] found in the mouse model that targeted-CEA CAR-T could remarkably reduce the proliferation and metastasis of CEA-positive liver HCC cells. Furthermore, CAR-T targeting MUC1 has been shown to specifically kill MUC1-positive HCC cells in vitro. The EGFR family of proteins is also expressed in hepatocytes, which provides a theoretical basis for the feasibility of CAR-T therapy for hepatocellular carcinoma targeting EGF. Meanwhile, a variety of HCC associated antigens, such as CEA, GPC3, NKG2D, MUC1, EpCAM, EGFRvIII, and CD133, have been used in clinical trials for HCC (Table 2). Due to the poor efficacy of current therapies for advanced HCC, researchers have great hopes for car-T therapy for HCC.

Glypican-3 (GPC3), a heparin sulfate proteoglycan, is highly expressed on the surface of HCC cells, but is rarely expressed in normal tissues. Researchers demonstrated that targeted GPC3 CAR-T can significantly eliminate GPC3-positive HCC cells and inhibit the proliferation of malignant tumor cells [102]. At present, there are the most clinical studies on targeted GPC3 CAR-T in HCC (Table 2). In this study (NCT02715362), transcatheter Arterial injection (TAI) is adopted to mediate the injection of CAR-T into the body, which is regarded as a malignancy intervention therapy approach. The hope is that this will increase the local CAR-T population and reduce potential side effects. Novel drug delivery methods have emerged in the treatment of HCC by CAR T, and more clinical studies are needed to verify the efficacy. These indicate that increasing the car-T cells concentration of tumors as much as possible under the premise of safety is the current difficulty that car-T therapy needs to overcome.

Alpha-fetoprotein (AFP) is an important biomarker in HCC, and AFP-L 3 is a subtype of AFP. Researchers found that AFP-L3 is specifically expressed in HCC, and AFP-L3 may be a promising target for CAR-T therapy for HCC [103]. Relevant clinical study (NCT03349255) has also been carried out, but it is not known why they have been stopped. Sperm protein 17 (Sp17) exerts a crucial function in the diagnosis of HCC and malignancy differentiation [104]. The specific expression of Sp17 in HCC cells is related to the pathological stage of HCC. Whether it can be used as a target for CAR therapy for HCC needs more studies to verify.

\section{Conclusion}

Researchers have invested a great deal of energy and material resources in the treatment of solid tumors in order to achieve the achievement of CAR-T in solid tumors as well as in hematologic tumors. So far, pre-clinical and clinical studies on the treatment of digestive system tumors by CAR-T have shown a certain anti-tumor effect, but there are still many studies terminating due to complications in clinical studies and few of them have been successful. Therefore, in the face of the current research on the treatment of DSMs by CAR-T, the search for specific expression of tumor antigens remains the focus of CAR-T therapy. Furthermore, CAR-T technology strategy was optimized to overcome the obstacles of CAR-T in the face of solid malignancies, including increasing the ability of CAR-T to infiltrate malignancy tissues, eliminating immunosuppression, improving CAR-T function, and reducing potential toxicity. At the same time, in addition to these strategies for making CAR-T work in solid malignancies, these technologies need to be made more likely to be widely used in clinical applications. Allogeneic CAR-T may be one way to achieve this goal by using healthy donor cells instead of cells from each patient.

In addition, the CAR - $\mathrm{T}$ technology combined other cancer adjuvant therapy is also a direction of tumor therapy. After all, preclinical and clinical studies of CAR - T in the DSMS have showed its strong antitumor activity. Regardless of whether it can heal the DSMS on its own, now under the premise of security, CAR - T technology combines chemotherapy, radiotherapy, targeted drug therapy and other immunotherapy can certainly let patients obtain good prognosis. We hope that there will be more clinical studies of CAR-T in combination with other cancer adjuvant therapies in the future, which will accelerate the application of CAR-T in DSMS.

Immunotherapy for CAR-T represents a new and powerful approach to cancer therapy, and many improvements have been made in target selection and structural optimization in the studies of tumors in the digestive system. But what is being done is not enough, and the development of CAR-T technology must be more closely integrated with other technologies, such as genome editing, immunocheckpoint inhibitors, and other adjuvant therapies, in order to successfully treat DSMS.

All clinical trials are available at www.clinicaltrials.gov (visit July $18,2020)$.

\section{References}

1. Siegel RL, Miller KD, Jemal A (2018) Cancer statistics, 2018 CA Cancer J Clin 68 7-30. [Crossref]

2. Feng RM, Zong YN, Cao SM (2019) Current cancer situation in China: good or bad news from the 2018 Global Cancer Statistics?. Cancer Commun (Lond) 39: 22. [Crossref]

3. Miller JF, Sadelain M (2015) The journey from discoveries in fundamental immunology to cancer immunotherapy. Cancer cell 27: 439-449. [Crossref]

4. Fournier C, Martin F, Zitvogel L (2017) Trial Watch: Adoptively transferred cells for anticancer immunotherapy. Oncoimmunology 6: e1363139. [Crossref]

5. Zhang H, Ye ZL, Yuan ZG (2016) New Strategies for the Treatment of Solid Tumors with CAR-T Cells. Int J Biol Sci 12: 718-729. [Crossref]

6. Heczey A, Louis CU, Savoldo B (2017) CAR T Cells Administered in Combination with Lymphodepletion and PD-1 Inhibition to Patients with Neuroblastoma. Mol Ther 25: 2214-2224. [Crossref]

7. Rupp LJ, Schumann K, Roybal KT (2017) CRISPR/Cas9-mediated PD-1 disruption enhances anti-tumor efficacy of human chimeric antigen receptor T cells. Sci Rep 7: 737. [Crossref]

8. Hegde UP, Mukherji B (2017) Current status of chimeric antigen receptor engineered $\mathrm{T}$ cell-based and immune checkpoint blockade-based cancer immunotherapies. Cancer Immunol Immunother 66: 1113-1121. [Crossref] 
9. Zhao Z, Xiao X, Saw P E, Wu W, Huang H, et al. (2020) Chimeric antigen receptor T cells in solid tumors: a war against the tumor microenvironment. Sci China Life Sci 63: 180-205. [Crossref]

10. Sadelain M, Rivière I, Brentjens R (2003) Targeting tumours with genetically enhanced T lymphocytes. Nat Rev Cancer 3: 35-45. [Crossref]

11. Bridgeman JS, Hawkins RE, Hombach AA (2010) Building better chimeric antigen receptors for adoptive T cell therapy. Curr Gene Ther 10: 77-90. [Crossref]

12. Stauss HJ, Morris EC, Abken H (2015) Cancer gene therapy with T cell receptors and chimeric antigen receptors. Curr Opin Pharmacol 24: 113-118. [Crossref]

13. Turtle CJ, Hudecek M, Jensen MC (2012) Engineered T cells for anti-cancer therapy. Curr Opin Immunol 24: 633-639. [Crossref]

14. Seliger B (2008) Different regulation of MHC class I antigen processing components in human tumors. J Immunotoxicol 5: 361-367. [Crossref]

15. Eshhar Z, Waks T, Gross G (1993) Specific activation and targeting of cytotoxic lymphocytes through chimeric single chains consisting of antibody-binding domains and the gamma or zeta subunits of the immunoglobulin and T-cell receptors. Proc Nat Acad Sci U S A 90: 720-724. [Crossref]

16. Harding FA, Mcarthur JG, Gross JA (1992) CD28-mediated signalling co-stimulates murine T cells and prevents induction of anergy in T-cell clones. Nature 356: 607-609. [Crossref]

17. Lenschow DJ, Walunas TL, Bluestone JA (1996) CD28/B7 system of T cell costimulation. Annu Rev Immunol 14: 233-258. [Crossref]

18. Bretscher PA (1999) A two-step, two-signal model for the primary activation of precursor helper T cells. Proc Natl Acad Sci U S A 96: 185-90. [Crossref]

19. Zhong XS, Matsushita M, Plotkin J (2010) Chimeric antigen receptors combining 4-1BB and CD28 signaling domains augment PI3kinase/AKT/Bcl-XL activation and CD8+ T cell-mediated tumor eradication. Mol Ther 18: 413-420. [Crossref]

20. Frigault MJ, Lee J, Basil MC (2015) Identification of chimeric antigen receptors that mediate constitutive or inducible proliferation of T cells. Cancer Immunol Res 3: 35667. [Crossref]

21. Kawalekar OU, O'connor RS, Fraietta JA (2016) Distinct Signaling of Coreceptors Regulates Specific Metabolism Pathways and Impacts Memory Development in CAR T Cells. Immunity 44: 380-90. [Crossref]

22. Long AH, Haso WM, Shern JF (2015) 4-1BB costimulation ameliorates T cell exhaustion induced by tonic signaling of chimeric antigen receptors. Nat Med 21: 58190. [Crossref]

23. Chmielewski M, Kopecky C, Hombach AA (2011) IL-12 release by engineered T cells expressing chimeric antigen receptors can effectively Muster an antigen-independent macrophage response on tumor cells that have shut down tumor antigen expression. Cancer Res 71: 5697-706. [Crossref]

24. Chmielewski M, Abken H (2015) TRUCKs: the fourth generation of CARs. Expert Opin Biol Ther 15: 1145-54. [Crossref]

25. Caruana I, Savoldo B, Hoyos V (2015) Heparanase promotes tumor infiltration and antitumor activity of CAR-redirected T lymphocytes. Nat Med 21: 524-529. [Crossref]

26. Chmielewski M, Hombach AA, Abken H (2014) Of CARs and TRUCKs: chimeric antigen receptor (CAR) T cells engineered with an inducible cytokine to modulate the tumor stroma. Immunol Rev 257: 83-90. [Crossref]

27. Liao W, Lin JX, Leonard WJ (2011) IL-2 family cytokines: new insights into the complex roles of IL-2 as a broad regulator of T helper cell differentiation. Curr Opin Immunol 23: 598-604. [Crossref]

28. Pegram HJ, Lee JC, Hayman EG (2012) Tumor-targeted T cells modified to secrete IL-12 eradicate systemic tumors without need for prior conditioning. Blood 119: 41334141. [Crossref]

29. Yeku OO, Purdon TJ, Koneru M (2017) Armored CAR T cells enhance antitumor efficacy and overcome the tumor microenvironment. Sci Rep 7: 10541. [Crossref]

30. Koneru M, Purdon TJ, Spriggs D (2015) IL-12 secreting tumor-targeted chimeric antigen receptor T cells eradicate ovarian tumors in vivo. Oncoimmunology 4: e994446. [Crossref]

31. You F, Jiang L, Zhang B (2016) Phase 1 clinical trial demonstrated that MUC1 positive metastatic seminal vesicle cancer can be effectively eradicated by modified Anti-MUC1 chimeric antigen receptor transduced T cells. Sci China Life Sci 59: 386-397. [Crossref]

32. Garlanda C, Dinarello CA, Mantovani A (2013) The interleukin-1 family: back to the future. Immunity 39: 1003-1018. [Crossref]
33. Hu B, Ren J, Luo Y (2017) Augmentation of Antitumor Immunity by Human and Mouse CAR T Cells Secreting IL-18. Cell Rep 20: 3025-3033. [Crossref]

34. Avanzi MP, Yeku O, Li X (2018) Engineered Tumor-Targeted T Cells Mediate Enhanced Anti-Tumor Efficacy Both Directly and through Activation of the Endogenous Immune System. Cell Reports 23: 2130-2141. [Crossref]

35. Ren J, Liu X, Fang C (2017) Multiplex Genome Editing to Generate Universal CAR T Cells Resistant to PD1 Inhibition. Clin Cancer Res 23: 2255-2266. [Crossref]

36. Gust J, Hay KA, Hanafi LA (2017) Endothelial Activation and Blood-Brain Barrie Disruption in Neurotoxicity after Adoptive Immunotherapy with CD19 CAR-T Cells. Cancer Discov 7: 1404-1419. [Crossref]

37. Bonifant CL, Jackson HJ, Brentjens RJ (2016) Toxicity and management in CAR T-cell therapy. Mol Ther Oncolytics 3: 16011. [Crossref]

38. Neelapu SS, Tummala S, Kebriaei P (2018) Chimeric antigen receptor T-cell therapy - assessment and management of toxicities. Nat Rev Clin Oncol 15: 47-62. [Crossref]

39. Klebanoff CA, Rosenberg SA, Restifo NP (2016) Prospects for gene-engineered T cell immunotherapy for solid cancers. Nat Med 22: 26-36. [Crossref]

40. Ahmed N, Brawley VS, Hegde M (2015) Human Epidermal Growth Factor Receptor 2 (HER2) -Specific Chimeric Antigen Receptor-Modified T Cells for the Immunotherapy of HER2-Positive Sarcoma. J Clin Oncol 33: 1688-96. [Crossref]

41. Lamers CH, Sleijfer S, Vulto AG (2006) Treatment of metastatic renal cell carcinoma with autologous T-lymphocytes genetically retargeted against carbonic anhydrase IX: first clinical experience. J Clin Oncol 24: e20-2. [Crossref]

42. Shah NN, Fry TJ (2019) Mechanisms of resistance to CAR T cell therapy. Nat Rev Clin Oncol 16: 372-85. [Crossref]

43. Morgan RA, Yang JC, Kitano M (2010) Case report of a serious adverse event following the administration of $\mathrm{T}$ cells transduced with a chimeric antigen receptor recognizing ERBB2. Mol Ther 2010, 18: 843-51. [Crossref]

44. Newick K, Moon E, Albelda SM (2016) Chimeric antigen receptor T-cell therapy for solid tumors. Molecular Therapy Oncolytics 3: 16006.

45. Koneru M, O'cearbhaill R, Pendharkar S (2015) A phase I clinical trial of adoptive T cell therapy using IL-12 secreting MUC-16(ecto) directed chimeric antigen receptors for recurrent ovarian cancer. J Transl Med 13: 102. [Crossref]

46. Wang LC, Lo A, Scholler J (2014) Targeting fibroblast activation protein in tumor stroma with chimeric antigen receptor $\mathrm{T}$ cells can inhibit tumor growth and augment host immunity without severe toxicity. Cancer Immunol Res 2: 154-66. [Crossref]

47. Mount CW, Majzner RG, Sundaresh S (2018) Potent antitumor efficacy of anti-GD2 CAR T cells in H3-K27M(+) diffuse midline gliomas. Nat Med 24: 572-579. [Crossref]

48. Morello A, Sadelain M, Adusumilli PS (2016) Mesothelin-Targeted CARs: Driving T Cells to Solid Tumors. Cancer Discov 6: 133-146. [Crossref]

49. Kloss CC, Lee J, Zhang A (2018) Dominant-Negative TGF- $\beta$ Receptor Enhances PSMA-Targeted Human CAR T Cell Proliferation and Augments Prostate Cancer Eradication. Mol Ther 26: 1855-1866. [Crossref]

50. Brown CE, Alizadeh D, Starr R (2016) Regression of Glioblastoma after Chimeric Antigen Receptor T-Cell Therapy. N Engl J Med 375: 2561-2569. [Crossref]

51. Katz SC, Burga RA, Mccormack E (2015) Phase I Hepatic Immunotherapy for Metastases Study of Intra-Arterial Chimeric Antigen Receptor-Modified T-cel Therapy for CEA+ Liver Metastases. Clin Cancer Res 21: 3149-3159. [Crossref]

52. Jackson HJ, Rafiq S, Brentjens RJ (2016) Driving CAR T-cells forward. Nat Rev Clin Oncol 13: 370-83. [Crossref]

53. Fesnak AD, June CH, Levine BL (2016) Engineered T cells: the promise and challenges of cancer immunotherapy. Nature reviews Cancer 16: 566-581. [Crossref]

54. Mikucki ME, Fisher DT, Matsuzaki J (2015) Non-redundant requirement for CXCR3 signalling during tumoricidal T-cell trafficking across tumour vascular checkpoints. Nat Commun 6: 7458. [Crossref]

55. Turley SJ, Cremasco V, Astarita JL (2015) Immunological hallmarks of stromal cells in the tumour microenvironment. Nat Rev Immunol 15: 669-682. [Crossref]

56. Parente-Pereira AC, Burnet J, Ellison D (2011) Trafficking of CAR-engineered human $\mathrm{T}$ cells following regional or systemic adoptive transfer in SCID beige mice. $J$ Clin Immunol 31: 710-8. [Crossref]

57. Tchou J, Zhao Y, Levine B L (2017) Safety and Efficacy of Intratumoral Injections of Chimeric Antigen Receptor (CAR) T Cells in Metastatic Breast Cancer. Cancer Immunol Res 5: 1152-1161. [Crossref] 
58. Mullins IM, Slingluff CL, Lee JK (2004) CXC chemokine receptor 3 expression by activated CD8+ T cells is associated with survival in melanoma patients with stage III disease. Cancer Res 64: 7697-701. [Crossref]

59. Harlin H, Meng Y, Peterson AC (2009) Chemokine expression in melanoma metastases associated with CD8+ T-cell recruitment. Cancer Res 69: 3077-3085. [Crossref]

60. Mlecnik B, Tosolini M, Charoentong P (2010) Biomolecular network reconstruction identifies T-cell homing factors associated with survival in colorectal cancer. Gastroenterology 138: 1429-1440. [Crossref]

61. Martinet L, Le Guellec S, Filleron T (2012) High endothelial venules (HEVs) in human melanoma lesions: Major gateways for tumor-infiltrating lymphocytes. Oncoimmunology 1: 829-39. [Crossref]

62. Evans SS, Repasky EA, Fisher DT (2015) Fever and the thermal regulation of immunity: the immune system feels the heat. Nat Rev Immunol 15: 335-349. [Crossref]

63. Moon EK, Carpenito C, Sun J (2011) Expression of a functional CCR2 receptor enhances tumor localization and tumor eradication by retargeted human $\mathrm{T}$ cells expressing a mesothelin-specific chimeric antibody receptor. Clin Cancer Res 17: 4719-4730. [Crossref]

64. Gobert M, Treilleux I, Bendriss-Vermare N (2009) Regulatory T cells recruited through CCL22/CCR4 are selectively activated in lymphoid infiltrates surrounding primary breast tumors and lead to an adverse clinical outcome. Cancer Res 69: 20002009. [Crossref]

65. Facciabene A, Peng X, Hagemann IS (2011) Tumour hypoxia promotes tolerance and angiogenesis via CCL28 and T(reg) cells. Nature 475(7355): 226-230. [Crossref]

66. Hillerdal V, Essand M (2015) Chimeric antigen receptor-engineered T cells for the treatment of metastatic prostate cancer. BioDrugs 29: 75-89. [Crossref]

67. Weinstock M, Mcdermott D (2015) Targeting PD-1/PD-L1 in the treatment of metastatic renal cell carcinoma. Ther Adv Urol 7: 365-377. [Crossref]

68. Varki V, Ioffe OB, Bentzen SM (2018) PD-L1, B7-H3, and PD-1 expression in immunocompetent vs. immunosuppressed patients with cutaneous squamous cell carcinoma. Cancer Immunol Immunother 67: 805-814. [Crossref]

69. Singer M, Wang C, Cong L (2016) A Distinct Gene Module for Dysfunction Uncoupled from Activation in Tumor-Infiltrating T Cells. Cell 166: 1500-11.e9. [Crossref]

70. Newick K, O'brien S, Moon E (2017) CAR T Cell Therapy for Solid Tumors. Annu Rev Med 68: 139-152. [Crossref]

71. Di S, Li Z (2016) Treatment of solid tumors with chimeric antigen receptor-engineered T cells: current status and future prospects. Sci China Life Sci 59: 360-369. [Crossref]

72. Abrahao-Machado LF, Scapulatempo-Neto C (2016) HER2 testing in gastric cancer: An update. World J Gastroenterol 22: 4619-4625. [Crossref]

73. Kurokawa Y, Matsuura N, Kimura Y (2015) Multicenter large-scale study of prognostic impact of HER2 expression in patients with resectable gastric cancer. Gastric Cancer 18: 691-697. [Crossref]

74. Sheffield BS, Garratt J, Kalloger SE (2014) HER2/neu testing in gastric cancer by immunohistochemistry: assessment of interlaboratory variation. Arch Pathol Lab Med 138: 1495-1502. [Crossref]

75. Zulfiqar M, Bluth MH, Bhalla A (2018) Molecular Diagnostics in Esophageal and Gastric Neoplasms: 2018 Update. Clin Lab Med 38: 357-365. [Crossref]

76. Whilding LM, Maher J (2015) ErbB-targeted CAR T-cell immunotherapy of cancer Immunotherapy 7: 229-241. [Crossref]

77. Kobold S, Steffen J, Chaloupka M (2015) Selective bispecific T cell recruiting antibody and antitumor activity of adoptive T cell transfer. J Natl Cancer Inst 107: 364. [Crossref]

78. Jiang H, Shi Z, Wang P (2019) Claudin18.2-Specific Chimeric Antigen Receptor Engineered T Cells for the Treatment of Gastric Cancer. J Natl Cancer Inst 111: 409418. [Crossref]

79. Ito T, Kajino K, Abe M (2014) ERC/mesothelin is expressed in human gastric cancer tissues and cell lines. Oncol Rep 31: 27-33. [Crossref]

80. Sotoudeh M, Shirvani SI, Merat S (2019) MSLN (Mesothelin), ANTXR1 (TEM8), and MUC3A are the potent antigenic targets for CAR T cell therapy of gastric adenocarcinoma. J Cell Biochem 120: 5010-5017. [Crossref]

81. Beatty GL, O'hara M (2016) Chimeric antigen receptor-modified T cells for the treatment of solid tumors: Defining the challenges and next steps. Pharmacol Ther 166: 30-39. [Crossref]
82. Watanabe K, Luo Y, Da T (2018) Pancreatic cancer therapy with combined mesothelinredirected chimeric antigen receptor $\mathrm{T}$ cells and cytokine-armed oncolytic adenoviruses. JCI Insight 3: e99573 [Crossref]

83. Beatty GL, O'hara MH, Lacey SF (2018) Activity of Mesothelin-Specific Chimeric Antigen Receptor T Cells Against Pancreatic Carcinoma Metastases in a Phase 1 Trial. Gastroenterology 155: 29-32. [Crossref]

84. Beatty GL, Haas AR, Maus MV (2014) Mesothelin-specific chimeric antigen recepto mRNA-engineered $\mathrm{T}$ cells induce anti-tumor activity in solid malignancies. Cancer Immunol Res 2: 112-20. [Crossref]

85. Lv J, Zhao R, Wu D (2019) Mesothelin is a target of chimeric antigen receptor T cells for treating gastric cancer. J Hematol Oncol 12: 18. [Crossref]

86. Maher J, Wilkie S (2009) CAR mechanics: driving T cells into the MUC of cancer. Cancer Res 69: 4559-4562. [Crossref]

87. Wilkie S, Van Schalkwyk MC, Hobbs S (2012) Dual targeting of ErbB2 and MUC1 in breast cancer using chimeric antigen receptors engineered to provide complementary signaling. J Clin Immunol 32: 1059-70. [Crossref]

88. Warneke VS, Behrens HM, Haag J (2013) Members of the EpCAM signalling pathway are expressed in gastric cancer tissue and are correlated with patient prognosis. $\mathrm{Br} \mathrm{J}$ Cancer 109: 2217-2227. [Crossref]

89. Deng Z, Wu Y, Ma W (2015) Adoptive T-cell therapy of prostate cancer targeting the cancer stem cell antigen EpCAM. BMC Immunol 16: 1. [Crossref]

90. Zingoni A, Molfetta R, Fionda C (2018) NKG2D and Its Ligands: "One for All, All for One”. Front Immunol 9: 476. [Crossref]

91. Antonangeli F, Soriani A, Cerboni C (2017) How Mucosal Epithelia Deal with Stress Role of NKG2D/NKG2D Ligands during Inflammation. Front Immunol 8: 1583. [Crossref]

92. Deng X, Gao F, Li N (2019) Antitumor activity of NKG2D CAR-T cells against human colorectal cancer cells in vitro and in vivo. Am J Cancer Res 9: 945-958. [Crossref]

93. Liu X, Sun M, Yu S (2015) Potential therapeutic strategy for gastric cancer peritoneal metastasis by NKG2D ligands-specific T cells. Onco Targets Ther 8: 3095-3104. [Crossref]

94. Moshitch-Moshkovitz S, Tsarfaty G, Kaufman DW (2006) In vivo direct molecular imaging of early tumorigenesis and malignant progression induced by transgenic expression of GFP-Met. Neoplasia 8: 353-63. [Crossref]

95. Giordano S, Bardelli A, Zhen Z (1997) A point mutation in the MET oncogene abrogates metastasis without affecting transformation. Proc Natl Acad Sci U S A 94: 13868-13872. [Crossref]

96. Lanitis E, Poussin M, Hagemann IS (2012) Redirected antitumor activity of primary human lymphocytes transduced with a fully human anti-mesothelin chimeric receptor Mol Ther 20: 633-43. [Crossref]

97. Katari U L, Keirnan J M, Worth A C (2011) Engineered T cells for pancreatic cancer treatment. $H P B$ (Oxford) 13: 643-50. [Crossref]

98. Abate-Daga D, Lagisetty KH, Tran E (2014) A novel chimeric antigen receptor against prostate stem cell antigen mediates tumor destruction in a humanized mouse model of pancreatic cancer. Hum Gene Ther 25: 1003-1012. [Crossref]

99. Chmielewski M, Hahn O, Rappl G (2012) T cells that target carcinoembryonic antigen eradicate orthotopic pancreatic carcinomas without inducing autoimmune colitis in mice. Gastroenterology 143: 1095-107.e2. [Crossref]

100. Posey AD, Jr., Schwab RD, Boesteanu AC (2016) Engineered CAR T Cells Targeting the Cancer-Associated Tn-Glycoform of the Membrane Mucin MUC1 Control Adenocarcinoma. Immunity 44: 1444-54. [Crossref]

101. Burga RA, Thorn M, Point GR (2015) Liver myeloid-derived suppressor cells expand in response to liver metastases in mice and inhibit the anti-tumor efficacy of anti-CEA CAR-T. Cancer Immunol Immunother 64: 817-829. [Crossref]

102. Gao H, Li K, Tu H (2014) Development of T cells redirected to glypican-3 for the treatment of hepatocellular carcinoma. Clin Cancer Res 20: 6418-6428. [Crossref]

103. Roberts LR (2016) Biomarkers for hepatocellular carcinoma. Clinical advances in hematology \& oncology: H\&O 14: 223-234. [Crossref]

104. Xia QY, Liu S, Li FQ (2013) Sperm protein 17, MAGE-C1 and NY-ESO-1 in hepatocellular carcinoma: expression frequency and their correlation with clinical parameters. Int J Clin Exp Pathol 1610-6. [Crossref] 
105. Liu H, Xu Y, Xiang J (2017) Targeting Alpha-Fetoprotein (AFP)-MHC Complex with CAR T-Cell Therapy for Liver Cancer. Clin Cancer Res 23: 478-488. [Crossref]

106. Teng R, Zhao J, Zhao Y (2019) Chimeric Antigen Receptor-modified T Cells Repressed Solid Tumors and Their Relapse in an Established Patient-derived Colon Carcinoma Xenograft Model. J Immunother 42: 33-42. [Crossref]

107. Li W, Guo L, Rathi P (2017) Redirecting T Cells to Glypican-3 with 4-1BB Zeta Chimeric Antigen Receptors Results in Th1 Polarization and Potent Antitumor Activity. Hum Gene Ther 28: 437-448. [Crossref]

108. Jiang Z, Jiang X, Chen S (2017) Anti-GPC3-CAR T Cells Suppress the Growth of Tumor Cells in Patient-Derived Xenografts of Hepatocellular Carcinoma. Front Immunol 7: 690. [Crossref]

109. Chen C, Li K, Jiang H (2017) Development of T cells carrying two complementary chimeric antigen receptors against glypican-3 and asialoglycoprotein receptor 1 for the treatment of hepatocellular carcinoma. Cancer Immunol Immunother 66: 475-489. [Crossref]

110. Maliar A, Servais C, Waks T (2012) Redirected T cells that target pancreatic adenocarcinoma antigens eliminate tumors and metastases in mice. Gastroenterology 143: 1375-84.e5. [Crossref]
111. Tao K, He M, Tao F (2018) Development of NKG2D-based chimeric antigen receptor-T cells for gastric cancer treatment. Cancer Chemother Pharmacol 82: 81527. [Crossref]

112. Zhao W, Jia L, Zhang M (2019) The killing effect of novel bi-specific Trop2/PD-L1 CAR-T cell targeted gastric cancer. Am J Cancer Res 9: 1846-1856. [Crossref]

113. Song Y, Tong C, Wang Y (2018) Effective and persistent antitumor activity of HER2-directed CAR-T cells against gastric cancer cells in vitro and xenotransplanted tumors in vivo. Protein cell 9: 867-878. [Crossref]

114. Wu D, Lv J, Zhao R (2020) PSCA is a target of chimeric antigen receptor T cells in gastric cancer. Biomarker Res 8: 3. [Crossref]

115. Han YL, Liu CY, Li GH, Li J, Lv X, et al. (2018) Antitumor effects and persistence of a novel HER2 CAR T cells directed to gastric cancer in preclinical models. Am J Cancer Res 8: 106-119. [Crossref]

116. Kim M, Pyo S, Kang C H (2018) Folate receptor 1 (FOLR1) targeted chimeric antigen receptor (CAR) T cells for the treatment of gastric cancer. PloS one 13: e0198347. [Crossref]

Copyright: (C2020 Zhang Z. This is an open-access article distributed under the terms of the Creative Commons Attribution License, which permits unrestricted use, distribution, and reproduction in any medium, provided the original author and source are credited. 